\title{
Hearing Handicap Inventory for the Elderly
}

National Cancer Institute

\section{Source}

National Cancer Institute. Hearing Handicap Inventory for the Elderly. NCI Thesaurus. Code C157291.

A self-assessment tool designed to assess the effects of hearing impairment on the emotional and social adjustment of elderly people. The inventory is comprised of two subscales: a 13-item subscale that explores the emotional consequences of hearing impairment, and a 12-item subscale that explores both social and situational effects. 